\title{
A Glimpse into the Clinical Profile and Diagnostic Difficulties Encountered in the Evaluation of Genitourinary TB
}

\section{Bhattacharjee $\mathrm{K}^{1 *}$, Agrawal $\mathrm{A}^{2}$ and Roy $\mathrm{S}^{2}$ \\ 1Department of Medicine, Silchar Medical College and Hospital, India \\ ${ }^{2}$ Department of Medicine, Silchar Medical College and Hospital, India}

*Corresponding author: Kallol Bhattacharjee, Professor, Department of Medicine, Silchar Medical College and Hospital, Silchar, Assam, India, Email: kbsilchar64@gmail.com

\section{Research Article \\ Volume 4 Issue 3}

Received Date: November 06, 2019

Published Date: November 29, 2019

DOI: 10.23880 /oajun-16000170

\section{Abstract}

Background: Tuberculosis is a major health problem in world and more so in a developing nation like India. As mentioned in the Global TB report 2017 the estimated incidence of TB in India was approximately 280,000 accounting for a huge burden. Genitourinary tuberculosis (GUTB) is a global disease which shows a more destructive behavior especially in the developing countries.

Aims and Objectives: To evaluate the clinical profile of GUTB patients and determine the typical and atypical presenting clinical features.

Materials and Methods: The study was a prospective observational study that included 28 patients of GUTB and done over a period of 36 months from 1st July 2016 to 30th June 2019. A detailed history regarding symptoms of TB, past history as well as family history of pulmonary tuberculosis was recorded and a thorough clinical examination performed. The necessary laboratory investigations were done in all the patients.

Results and Observations: There was a male preponderance in the incidence of GUTB and the most common clinical presentation was fever. The most common organ affected by GUTB was kidney.

Conclusion: Genitourinary Tuberculosis is a common cause of extra-pulmonary tuberculosis with a potential to cause significant morbidity. As it presents with non-specific vague symptoms, a high index of clinical suspicion is necessary to make a diagnosis of GUTB.

Keywords: GUTB; TB; Clinical Presentation; Global Disease; High Index; Clinical Suspicion; Significant Morbidity; Vague Symptoms

\section{Introduction}

Tuberculosis is a global health burden and more so for a developing nation like India. As mentioned in the Global TB report 2017, in India the estimated incidence of tuberculosis is calculated to the tune of 280,000 approximately which accounts for a huge burden of around $25 \%$ of the diagnosed TB cases in the whole world, the incidence in India being 211 per lac population and a mortality of 32 per lac population [1]. 
Therefore, India on its own accounts for nearly onefourth of global tuberculosis burden and it is estimated to kill approximately 7 lac individuals per year. Genitourinary tuberculosis (GUTB) is a global disease which shows a more destructive behaviour in developing countries. The term "Genitourinary tuberculosis" was first coined by Wildbolz in 1937. It is the third most common site of extra pulmonary tuberculosis and comprises 14$41 \%$ of total extra pulmonary TB burden [2,3]. Usually, it results from haematogenous spread following pulmonary tuberculosis. However, any active lesion in the kidney may be clinically dormant for years while irreversible renal parenchymal destruction occurs. If identified early, it is a completely curable condition. Clinician's across the world find it extremely difficult to assess the true incidence and prevalence of GUTB and as such there is paucity of literature on this entity. Silchar Medical College and Hospital is the sole tertiary care centre located in the southern region of Assam and also serves neighboring states including Mizoram, Tripura, Manipur and Meghalaya. A study on this particular topic has not been conducted in these parts of the world before.

\section{Aims and Objectives}

To evaluate the clinical profile of GUTB patients and determine the typical and atypical presenting clinical features.

\section{Materials and Methods}

\section{Study Setting}

This study was conducted in the Department of Medicine, Silchar Medical College and Hospital, Silchar, Assam, India.

\section{Period of Study}

The present study was of 36 months duration commencing from $1^{\text {st }}$ July 2016 to $30^{\text {th }}$ June 2019.

\section{Sample Size}

Indoor patients, 28 in number admitted in the above setup during the period of study and were randomly selected for the purpose based on the fulfillment of the inclusion and exclusion criteria. A written and informed consent was taken in all cases.

\section{Study Design}

It was a single centered hospital based prospective observational study.

\section{Methodology}

A detailed history regarding symptoms of TB, past history as well as family history of pulmonary tuberculosis was recorded and a thorough clinical examination was done in all the patients. Laboratory investigations carried out included a complete blood count, three morning samples of urine for AFB smear, routine examination and AFB cultures, serum chemistry including renal function test, chest skiagram, plain X-ray abdomen and intravenous urogram and virology including voluntary HIV testing. CT scan was advised in selected patients to confirm findings of IVU. AFB cultures were done on LJ medium and also using BACTEC. AFB smear was taken as presumptive of diagnosis while AFB cultures were taken as definitive of the diagnosis and so was the histology wherever and whenever applicable. In others, the diagnosis rested on clinical and radiological features in an appropriate setting. IVU was the most important diagnostic tool under these circumstances. Subtle findings were elaborated and confirmed by CT scanning.

\section{Statistical Analysis}

It was performed using the SPSS version 20.0. The data collected was tabulated in MS Excel and subjected to statistical analysis. Being an observational study, descriptive statistics like percentages, proportions, etc. were used to describe the results.

\section{Results and Observations}

A total of 28 patients were diagnosed to have genitourinary tuberculosis in the study period. The profiles of the diagnosed cases are depicted in the following figures and tables wherever applicable. The figures and tables are placed in accordance with appropriate headings and subheadings (Figure 1).

\section{Gender Distribution of the cases}

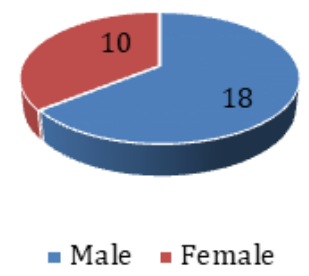

Figure 1: Gender distribution of the cases. 
In our study out of the total number of cases, 18 cases were male and 10 cases were female thus predicting a male preponderance in the incidence of GUTB. Majority of the cases (39.3\%) were older than 50 years (Tables 1 \& 2).

\begin{tabular}{|c|c|c|}
\hline Age group (in years ) & No. of cases & Percentage \\
\hline$<30$ years & 10 & 35.7 \\
\hline $30-50$ years & 7 & 25 \\
\hline$>50$ years & 11 & 39.3 \\
\hline
\end{tabular}

Table 1: Age distribution of the cases.

\begin{tabular}{|c|c|c|}
\hline Symptom & No. of cases & Percentage \\
\hline Fever & 22 & 78.5 \\
\hline $\begin{array}{c}\text { Burning micturition } \\
\text { and frequency }\end{array}$ & 13 & 46.5 \\
\hline Hematuria & 7 & 25 \\
\hline Loin pain & 9 & 32.1 \\
\hline Renal insufficiency & 3 & 10.7 \\
\hline Infertility & 2 & 7.1 \\
\hline Hemospermia & 1 & 3.6 \\
\hline
\end{tabular}

Table 2: Symptoms at Presentation.

In the present study most common symptom was fever seen in $78.5 \%$ cases whereas hemospermia was the least common symptom seen in only 1 male patient (Tables 3 \& 4, Figure 2).

\begin{tabular}{|c|c|}
\hline Duration(years) & No. of cases \\
\hline$<1$ & 1 \\
\hline $5-J a n$ & 3 \\
\hline$>5$ & 2 \\
\hline
\end{tabular}

Table 3: Timeline of past episode of PTB.

\begin{tabular}{|c|c|c|}
\hline & No. of cases & Percentage \\
\hline HIV & 2 & 7.1 \\
\hline Hepatitis B & 0 & 0 \\
\hline Hepatitis C & 0 & 0 \\
\hline
\end{tabular}

Table 4: Association with viral infections.

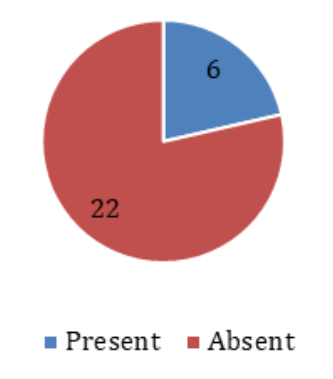

Figure 2: History of Pulmonary TB.
In the present study 2 cases had association with viral infections and in both the cases it was HIV. There was no association of Hepatitis B and $\mathrm{C}$ virus in any patients in our study (Table 5 \& Figure 3 ).

\begin{tabular}{|c|c|c|}
\hline BMI & No. of cases & Percentage \\
\hline$<18.5$ & 8 & 28.6 \\
\hline $18.5-24.9$ & 16 & 57.1 \\
\hline $25-29.9$ & 3 & 10.7 \\
\hline$>30$ & 1 & 3.6 \\
\hline
\end{tabular}

Table 5: Categorization of patient on the basis of BMI.

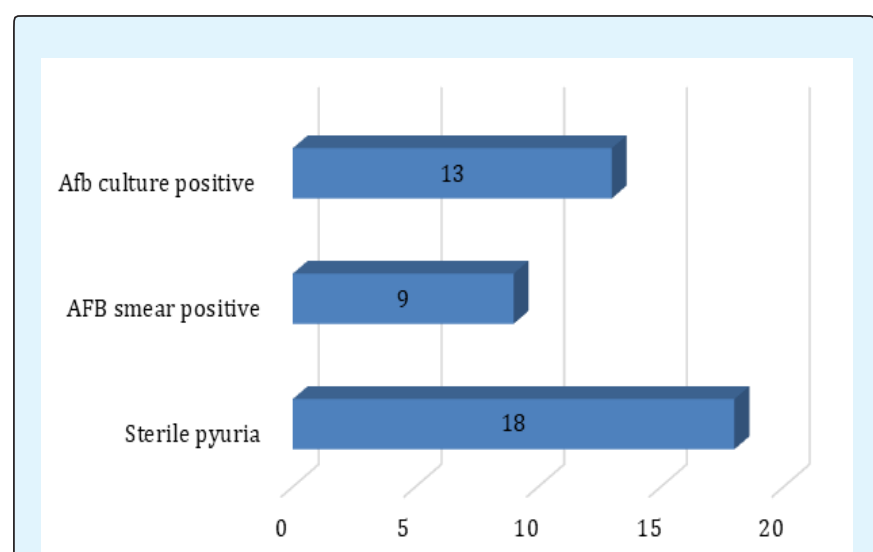

Figure 3: Findings of Urine Examination.

Among the diagnostic modalities, AFB culture was positive in 13 patients whereas AFB smear was positive only in 9 cases in the present study (Table 6).

\begin{tabular}{|c|c|c|}
\hline Finding & No. of cases & Percentage \\
\hline $\begin{array}{c}\text { Renal Cavitation or } \\
\text { scarring }\end{array}$ & 12 & 42.9 \\
\hline Hydronephrosis & 1 & 3.6 \\
\hline Renal abscess & 2 & 7.1 \\
\hline Thimble bladder & 2 & 7.1 \\
\hline $\begin{array}{c}\text { Ureteric stricture/ } \\
\text { Hydroureter }\end{array}$ & 4 & 14.3 \\
\hline $\begin{array}{c}\text { Tobacco pouch } \\
\text { appearance }\end{array}$ & 1 & 3.6 \\
\hline Unspecified or normal & 6 & 21.4 \\
\hline
\end{tabular}

Table 6: Radiographic findings in the cases.

Renal cavitation or scarring was the most common radiological finding in our study. A significant number of cases $(21.4 \%)$ in this study had unspecified or normal radiological picture (Table 7 \& Figures 4-6). 


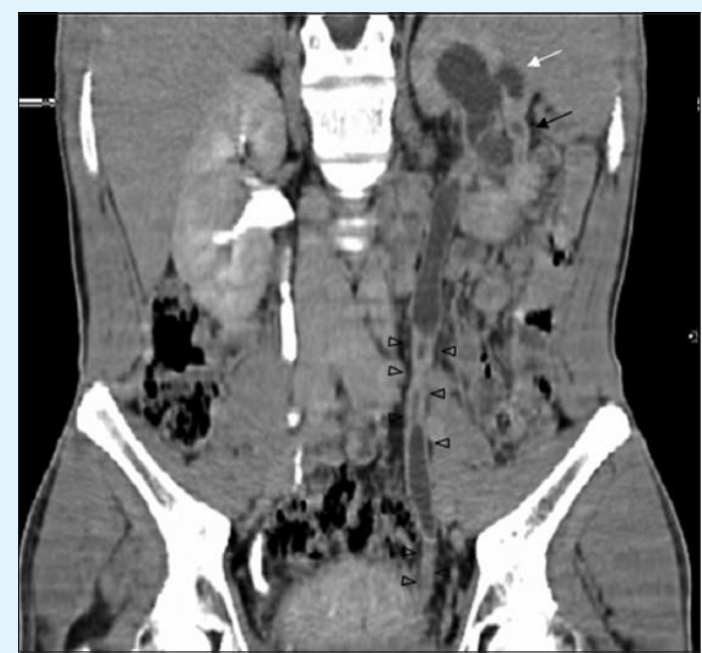

Figure 4: CT revealing multiplicity of findings in urinary TB-uneven caliectasis with no obvious pelvic dilatation, parenchymal scarring (black arrow), and cavity communicating with PCS (white arrow), urothelial thickening and multiple ureteral strictures (black arrowheads) [15].

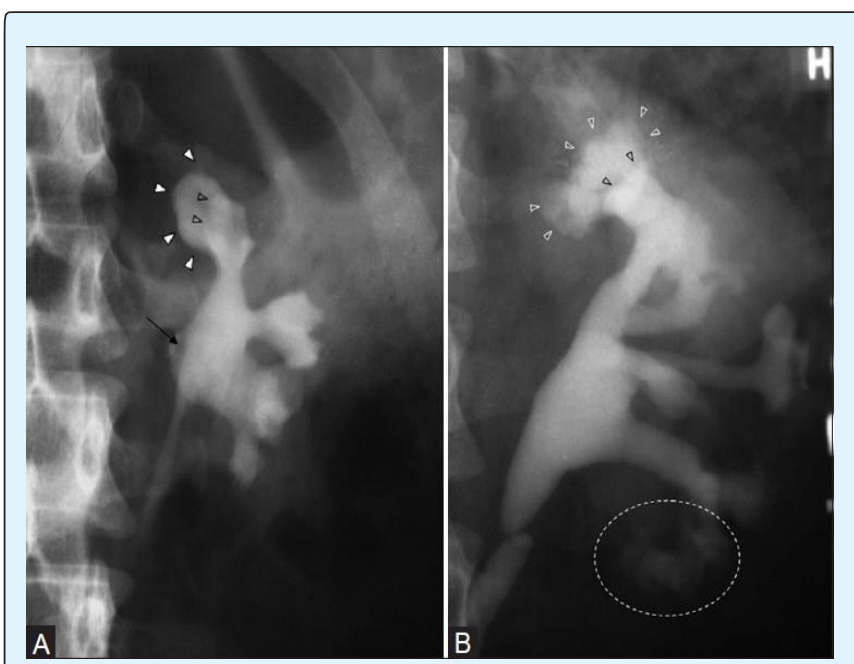

Figure 5 (A,B): (A) Intravenous urogram revealing a "hiked up" renal pelvis (arrow). Tuberculosis cavity (white arrowheads) communicating with the upper group of calyces. Black arrowheads represent medial border of a compound upper calyx, (B) Intravenous urogram revealing fluffy cavities (white arrowheads) communicating with a compound upper calyx (black arrowheads). Odd-shaped pockets of contrast communicating with a lower calyx (and with each other) [circled area], represent caseated necrotic cavities [16].

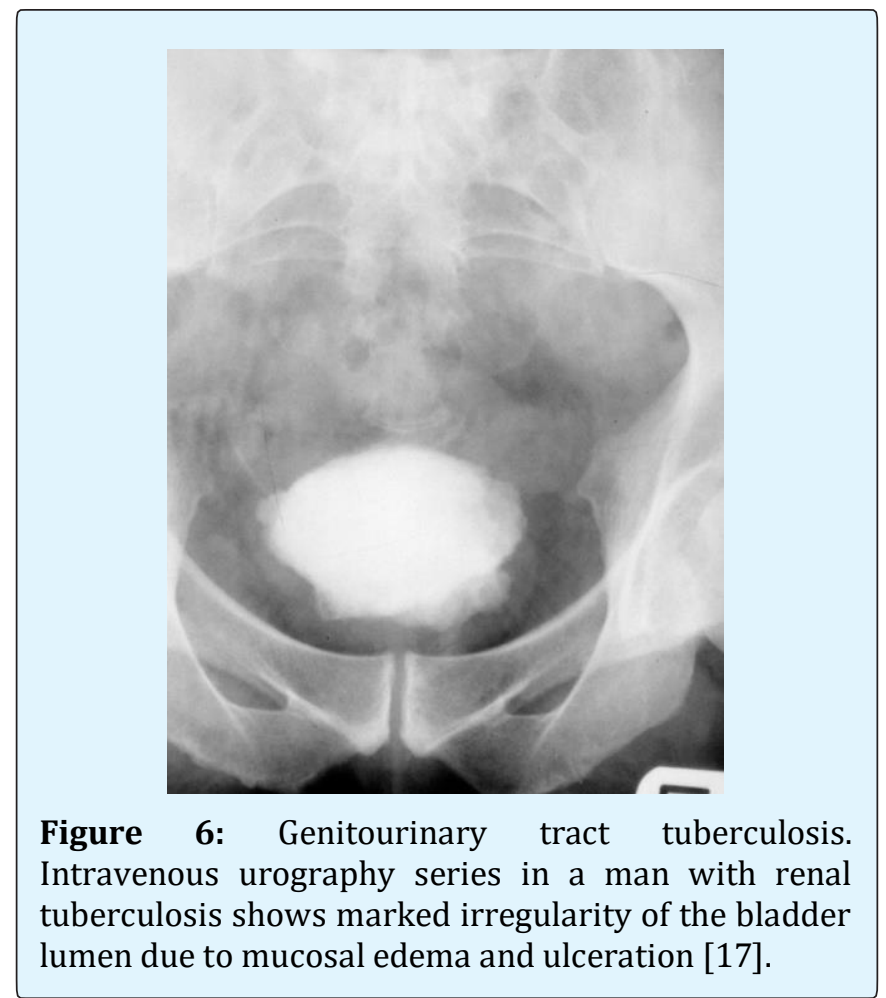

\begin{tabular}{|c|c|c|}
\hline Organ Involved & No. of cases & Percentage \\
\hline Kidney & 20 & 71.4 \\
\hline Ureter & 4 & 14.3 \\
\hline Bladder & 2 & 7.1 \\
\hline Testis & 1 & 3.6 \\
\hline Fallopian tube & 1 & 3.6 \\
\hline
\end{tabular}

Table 7: Frequency of various organ involvements in cases of GUTB.

Kidney was the most common organ involved (71.4\%) as observed in our study followed by Ureter which was involved in $14.3 \%$ of the cases as observed in this study.

\section{Discussion}

Amongst 28 patients diagnosed with GUTB, there were $18(64.3 \%)$ males and 10 (35.7\%) females. The male preponderance was also reported by Krishnamoorty, et al. [4], Najar MS, et al. [5] and Warren, et al. [6]. The age of the patients in our study varied between 19 and 59 years (average 31.6 years). The average age in the studies by Krishnamoorty, et al. and MS Najar, et al. were 35.4 and 35.2 years respectively. Lee, et al. [7] reported mean age of 45 years. The original pulmonary infection is followed by a latent period of considerable length ranging from 5 to 40 years before the appearance of clinical renal disease which is probably why renal involvement is rare before the age of 20 years [8]. 
The duration of symptoms varied from 2 months to 3 years (average 5 months). In the present series, 6 (21.4\%) patients had history of being treated for pulmonary TB in the past. Becker JA [9] observed association with pulmonary tuberculosis and GUTB in less than 5\% in all GUTB patients they encountered in their series and approximately $50 \%$ of them had reported a history of pulmonary TB in the past which differed from the observations in the present series whereas similar findings were observed by Lee, et al. who reported $22 \%$ incidence of past history of TB in their study group. N.P. Buchholz, et al. [10] reported 11\% incidence of past extra pulmonary TB but no PTB in their study with 55 GUTB patients which again are in contrast to the present study.

The main clinical features included fever followed by symptomatology related to lower urinary tract which were most commonly seen and observed in 13(46.5\%) patients in the present study. Loin pain was present in 9 patients $(32 \%)$. Hematuria was present in 7 patients $(25 \%)$ and 3 patients $(10.7 \%)$ had renal insufficiency. Out of total cases, $2(7.1 \%)$ patients gave history suggestive of infertility. The other notable symptoms in GUTB cases were weight loss, backache, anorexia and abdominal pain. GUTB characteristically presents with localized symptoms rather than the constitutional ones. Similar findings with slight variations were reported by Krishnamoorty, et al., MS Najar, et al., Lee, et al. and N.P. Buchholz, et al. As Chang had once rightly said about urogenital tuberculosis, "The kidney is an inarticulate organ; its vocal cords are the bladder" [11]. Impairment of bladder gives rise to the classical symptoms.

The detection of Mycobacterium tuberculosis by culture and its isolation using the standard protocol is the gold standard method for diagnosing tuberculosis involving any organs. In suspected cases of GUTB, it is usually searched in the urine samples. 'Sterile pyuria' was considered classical for GUTB. It was found in 18 (64.3\%) cases in our study. As per the study by Garcio-Tello, et al. [12], sterile pyuria was observed in $46 \%$ cases with GUTB. However sterile pyuria is not a specific diagnostic armament for GUTB as it is also found in other conditions like Chlamydia infection or in cases with intra-abdominal pathology like acute appendicitis [13]. The urine AFB smear test is simple, economical, and rapid but with low sensitivity. It was positive in $9(32.1 \%)$ cases in our study. The ultimate tool for diagnosis of GUTB which can very well be described as the gold standard is the detection and isolation of acid-fast bacilli (AFB) in urine culture, which has a $37-79 \%$ sensitivity rate 13 with added advantage of drug sensitivity testing. AFB culture was positive in 13 cases (46.4\%) in our study which is in contrast to Krishnamoorty, et al. where they found AFB culture to be positive only in $5 \%$ of the cases. However, this test can take up to 8 weeks for a result unless the modern techniques are applied.

Radiological findings are not readily diagnostic for GUTB but the intravenous urograms and the CT scan may be extremely useful in the differential diagnosis of renal tuberculosis from other infections and granulomatous entities. Plain X-ray of the chest should be undertaken in all suspected cases. The gross stricture, cavities and calcifications of advanced renal tuberculosis are distinctive. Tubercular involvement of ureter causes scarring and stricture formation leading to obstructive uropathy and hydroureteronephrosis. Genital TB in female is characterised by tobacco-pouch appearance of the fallopians. In our study, renal cavitation (42.9\%) followed by ureteric stricture (14.3\%) were the most common findings which are comparable to the existing world literature which includes the study by MS Najar, et al. where renal distortion, cavitation and scarring were seen in $42 \%$ of the cases.

As Kidney receives about 22\% of total cardiac output, it is vulnerable to haematogenous seeding of the mycobacterium and thereby is the predominant organ involved in GUTB. It accounted for $71.4 \%$ cases in our study. Our findings were supported by Lee, et al. (80.2\%), Krishnamoorty, et al. (63.4\%). In contrast, Orakwe, et al. [14] found renal involvement in only $16.3 \%$. Ureter and bladder $(14.3 \%$ and $7.1 \%)$ were next most common sites being in continuity with kidney. Testis was involved in 1 patient $(5.5 \%$ of all male patients) while fallopian tube was involved in 1 patient ( $10 \%$ of female). Orakwe, et al. found ureter and bladder involvement at $4.7 \%$ and $7 \%$ respectively in their series. Krishnamoorty et al found testis and epididymis involvement in 6 cases in their series but there was no case with involvement of fallopian tube [15-17].

\section{Conclusion}

Genitourinary Tuberculosis is a common cause of extra-pulmonary tuberculosis with a potential to cause significant morbidity. As it presents with non-specific vague symptoms, clinical suspicion of sufficient magnitude is necessary for the diagnosis of GUTB.

\section{Limitations of the Study}

The present study was a single centered one covering a limited geographical area. A multi centric approach with the coverage of wider geographical location covering 
diverse sections of the society would have been desirable for this study.

\section{References}

1. WHO Global TB report 2017.

2. Goel A, Seth A, Kumar R (2002) Autocystectomy following extensive genitourinary tuberculosis: Presentation and management. Int Urol Nephrol 34(3): 325-327.

3. Kennedy DH (1989) Extra pulmonary tuberculosis. In: Ratledge $\mathrm{C}$, et al. (Eds.), The Biology of the Mycobacteria. 3rd (Edn.), New York, Academic Press, pp: 245-284.

4. Krishnamoorthy S, Palaniyandi V, Kumaresan N, Govindaraju S, Rajasekaran J, et al. (2017) Aspects of Evolving Genito Urinary Tuberculosis-A Profile of Genito Urinary Tuberculosis (GUTB) in 110 Patients. J Clin Diagn Res 11(9): 1-5.

5. Najar MS, Bhat MA, Wani IA, Banday KA, Reshi AR, et al. (2003) Profile of renal tuberculosis in 63 patients. Indian J Nephrol 13: 104-107.

6. Warren D, Johnson Jr, Christopher W, Johnson Franklin C (2002) Lowe Tuberculosis and parasitic diseases of the genito urinary system, Campbell's Urology. $8^{\text {th }}$ (Edn.), Pennsylvania: Saunders, pp: 744763.

7. Lee JY, Park HY, Park SY, Lee SW, Moon HS, et al. (2011) Clinical Characteristics of Genitourinary Tuberculosis during a Recent 10-Year Period in One Center. Korean J Urol 52(3): 200-205.
8. Merchant SA (1993) Tuberculosis of the genitourinary system. Indian J Radiol Imaging 3: 253274.

9. Becker JA (1988) Renal tuberculosis. Urol Radiol 10(1): 25-30.

10. Buchholz N, Salahuddin S, Haque R (2000) Genitourinary tuberculosis: A profile of 55 inpatients. J Pak Med Assoc 50(8): 265-269.

11. Gokalp A, Gultekin EY, Ozdamar S (1990) Genitourinary tuberculosis: a review of 83 cases. Br J Clin Pract 44(12): 599-600.

12. Garcia-Tello A, Cacho J, Hernandez E, Palou J, Sanchez-Chapado M, et al. (2010) Descriptive analysis of a series of male genital tuberculosis with emphasis on diagnostic and therapeutic data. Eur Urol 9: 173

13. Sanchia G, Raj Persad (2015) Sterile pyuria: a forgotten entity. Ther Adv Urol 7(5): 295-298.

14. Orakwe JC, Okafor PI (2005) Genitourinary tuberculosis in Nigeria; a review of thirty-one cases. Niger J Clin Pract 8(2): 69-73.

15. http://www.ijri.org/viewimage.asp?img=IndianJRadi olImaging_2013_23_1_64_113617_f10.jpg.

16. http://www.ijri.org/viewimage.asp?img=IndianJRadi olImaging_2013_23_1_46_113615_u8.jpg.

17. https://emedicine.medscape.com/article/381509overview\#a2. 